\title{
APPLICATION OF A THERMAL MANNEQUIN TO THE ASSESSMENT OF THE HEAT INSULATING POWER OF PROTECTIVE GARMENTS FOR PREMATURE BABIES
}

\author{
Izabella Krucińska1, Ewa Skrzetuska1', Krzysztof Kowalski² \\ 'Lodz University of Technology, Department of Material and Commodity Sciences and Textile Metrology \\ ${ }^{2}$ Lodz University of Technology, Department of Knitting Technology
}

\begin{abstract}
:
In this study, the new tool for measuring thermal insulating power of garments for premature babies under coupled heat and moisture transport was developed. The thermal mannequin corresponds to the body weight and size of a premature baby born in the thirty fourth week of pregnancy. The mannequin surface temperature can be set at various levels, while the heat loss is measured in $\mathrm{W} / \mathrm{m} 2$. The mannequin is divided into eleven independent heating zones and seven independent zones of moisture evolution. The study also presents the test results of heat insulating power obtained for the newly developed garment set with commercially available garment set for babies, conducted under different climatic conditions. The results exhibit the advantage of the new material construction of the garment over the commercially available one.
\end{abstract}

\section{Keywords:}

model, thermal mannequin, newborn, heat insulating capability

\section{INTRODUCTION}

World statistics show a constantly growing level of premature births. American researchers have observed that the percentage of babies born before the thirty second week of pregnancy does not increase, whereas the number of babies born between the 34th and 36th week of pregnancy increases with each year. The newborn babies born within this group constitute over $70 \%$ of all the premature babies.[1,2] In Poland, every year about 40 thousand of premature infants are born, that it, about $10 \%$ of deliveries. Therefore, in recent years, the subgroup of newborns defined above has become the subject of increasing interest.

For many years, studies have been carried out on the thermal resistance of hospital bed-clothes with the use of children thermal mannequins.[3,4] This is connected with the fact that premature babies are very susceptible to heat loss on account of their large external surface in relation to body weight, thin immature skin, corneal layer absence, panniculus adiposus lack, brown fatty tissue absence, inefficient mechanism of "chills" and a weak vasomotor response. It has been found that in the case of premature babies with a low birth weight, in the first $24 \mathrm{~h}$ of their life, the water loss amounts to $150 \mathrm{ml}$ per $1 \mathrm{~kg}$ of body weight, which can lead to disturbances in electrolyte equilibrium. For comparison, in the case of babies born after the 30th week of pregnancy, the loss of water amounts to $12 \mathrm{ml} / \mathrm{kg} /$ day. [5] For a normal premature baby's development, it is essential to provide a stable temperature and humidity of the microenvironment. The maintenance of thermally neutral environment within a very narrow temperature range from $36.5^{\circ} \mathrm{C}$ to $37.5^{\circ} \mathrm{C}$ is necessary to minimize the consumption of oxygen and calories by a newborn baby.[6] The maintenance of a constant temperature is also necessary to keep the thermal balance.
The stabilization of newborn thermal environment and avoidance of thermal stress is of importance for short- and longterm effects.[7] One third of infants with birth weight $\leq 1000$ $\mathrm{g}$ had hypothermia after being transported from one hospital to another, despite active warming.[8] Newborns lose great amounts of heat through head due to the large skin surface, which can result in hypothermia. This in turn can lead to high consumption of oxygen and glucose (hypoglycemia), high energy expenditure connected with the body weight reduction, lethargy or hypotonia, blood vessel spasm and even thermal shock. $[9,10]$

Researchers of the Picardie Jules Verne University have performed tests connected with the assessment of differences in the heat insulating power of naked and dressed (including caps) newborns, using a thermal mannequin (Fig. 1) that simulated a newborn with a low birth weight. The experimental tests were carried out in a closed incubator at three different temperatures $\left(29^{\circ} \mathrm{C}, 32^{\circ} \mathrm{C}\right.$ and $\left.34^{\circ} \mathrm{C}\right)$. The tests show that the cap put on the thermal mannequin causes a decrease in heat loss on an average by $18.9 \%$.
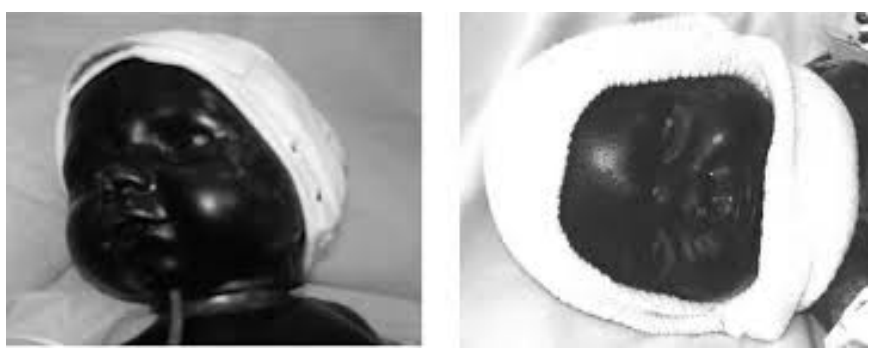

Fig. 1. Thermal mannequin simulating a newborn with a low birth weight[11] 
The researchers have concluded that this phenomenon can be a reason for over warming of newborn babies' brains. They suggest that babies left in an incubator should have their body covered and cap taken off. Exceptions are babies with hypothermia who should be provided with thermal balance.[11]

Global heat transport in the macro-scale can be determined by means of balance formulation with the term describing sweat evaporation.[11,12] Analyzing these equations,[17] it can be concluded that the experimental determination of the heat insulating power of protective garments for premature babies seems to be legitimate. This is possible through constructing a thermal mannequin that makes it possible to assess the heat insulating power of particular garment parts of the newborn garment. The thermal mannequins known so far were suitable only to measure the thermal insulating power.[3,4,13-15] Researchers of the Universite de Picardie Jules Verne have assessed the body heat losses between mannequins with small and large body dimensions of premature infants, using two anthropomorphic thermal mannequins of newborns weighing $900 \mathrm{~g}$ and $1800 \mathrm{~g}$ (Fig. 2).[18]

A successive technologically advanced solution is the thermal mannequin worked out by the Silesian University of Technology. It is a copper anthropomorphic thermal mannequin of a newborn (Fig. 3) for testing the convectional and radiation heat exchange with environment in an air-conditioning chamber. It makes it possible to measure the stream of lost heat at selected average skin temperatures and surrounding air.[19]

Any presented mannequin has not simulated the conditions of the coupled heat and moisture transfer between the body of a newborn and the surroundings. Therefore, the basic aim of the study was to construct a measurement tool reproducing the newborn skin in the form of a mannequin that would allow one to assess the heat insulating capability of various parts of the newborn garment and the resistance of water vapor and heat insulation under conditions of simulated sweat secretion.

The maintenance of proper body temperature and humidity of premature babies is of paramount importance for their survival. Literature data and information obtained in the Neonatology Clinic of the Polish Mother's Memorial Hospital Institute show that a higher surrounding temperature and higher humidity contribute to a lower mortality of newborns with a low birth weight. These parameters influence the maintenance of proper thermo-regulation that is a key element of the premature newborn care. The loss of heat by evaporation is a process absorbing energy, evoked by water evaporation from skin or mucous membranes. The evaporation of each gram of water results in a loss of about $0.58 \mathrm{kcal}$, which equals about $20 \mathrm{~W}$ of heat. A premature infant skin has an underdeveloped horny layer, which causes an essential increase in the trans-epidermal water loss and a decrease in its protective possibilities. The optimal environment temperature for newborns is well defined for various body weights and maturation stages. On the other hand, it seems that there is no information regarding the effect of the composition and garment structure of the fabric's raw material on the maintenance of a premature baby's thermal balance in various development phases.
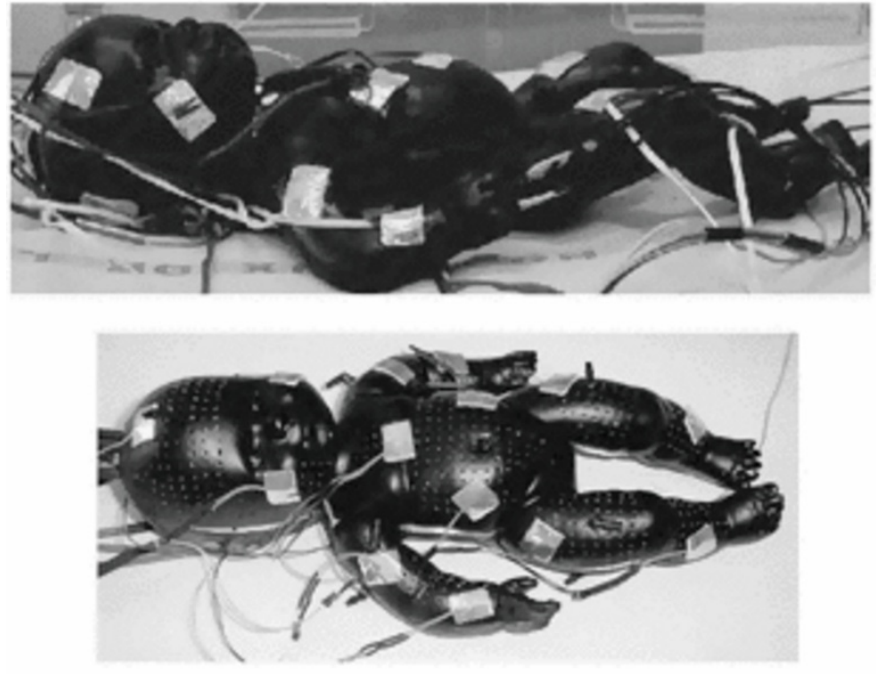

Fig. 2. Thermal mannequins corresponding to the infant weight of1800g and $900 \mathrm{~g}[18]$

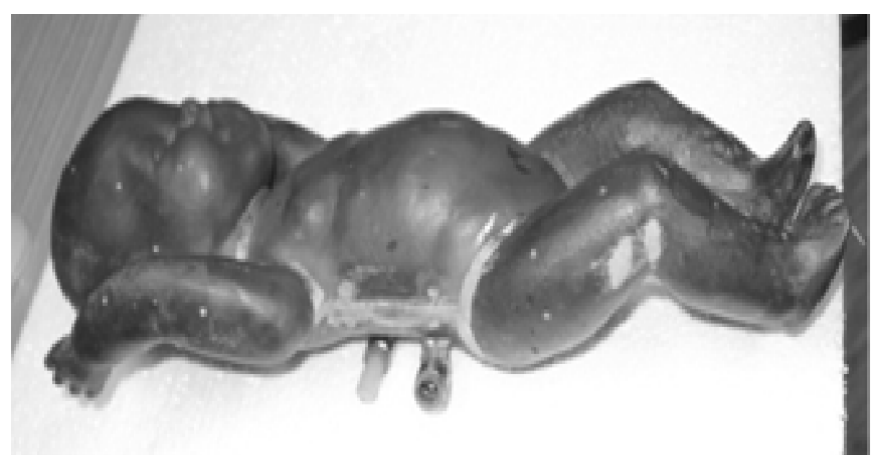

Fig. 3. Copper anthropomorphic thermal mannequin of a newborn[19]

Another essential aim of the study was to examine 18 different variants of knitted fabrics, specially made to provide premature babies with physiological comfort and to select an optimal structure of knitted fabric guaranteeing the warmth retention for premature babies under conditions of intensive moisture secretion and blocking moisture transport from the premature infant skin to the environment. Investigations were carried out with the use of conventional two-layer knitted fabrics to provide physiological comfort as well as knitted fabrics with on-conventional structure protected by a patent. Moreover, the authors analyzed the influence of the sweat secreted on the heat insulating power of a commercial cotton garment set for babies under conditions outside incubator. Author's solution of a garment made of two-layer bamboo viscose-polyester knitted fabric was also tested in the study.

\section{Test methods}

\section{Characteristics of measurement tool for the assessment of biophysical properties of garments for infants}

The assessment of the thermo-insulating properties of garments for premature babies was performed with the use of the premature baby thermal mannequin with a function of moisture secretion in its particular anatomic zones (Fig. 4). This mannequin was made by the ATT Wladyslaw Tarnowski Company. 
The mannequin model corresponds to the size and proportions of a baby's body with birth weight of $1500 \mathrm{~g}$. The mannequin dimensions have been established on the basis of real dimensions of premature babies born in the Baby Health Center in the Department of Neonatology in 2012. The most essential feature of the solution proposed is the possibility of a full continuous controlling of the moisture emission within the range of physiological values. The total mannequin surface amounts to $1100 \mathrm{~cm}^{2} .450$ miniature moisture emission points (Fig. 5) are located in the external polymeric coating imitating the skin and controlled in 7 independent zones (head center, head back, face, torso, back, hands, and legs).

The water emission rate is regulated within the range from 1 to $80 \mu \mathrm{l} / \mathrm{h} / \mathrm{cm}^{2}$.

This mannequin also consists of 11 independent heating zones: face, head, occiput, chest, abdomen, back, bottom, left hand, right hand, left leg, right leg, positioned by means of computer software, which is shown in Fig. 6. Each of the zones can be separately controlled, which makes it possible to set different temperatures and levels of moisture emission in particular measurement zones. This relates to the fact that an infant as an adult person secretes different amounts of sweat in different body parts.

Additionally, the mannequin is equipped with the function of mixing since it was accepted that the urination by a baby can also influence its biophysical comfort and thermo-regulation.

The mannequin can operate at ambient temperature from $10^{\circ} \mathrm{C}$ to $44^{\circ} \mathrm{C}$ and humidity from $20 \%$ to $90 \%$. On account of the necessity of simulating the environment conditions as well as incubatory conditions, the mannequin was located in a large-size chamber to control climatic conditions within the temperature range from $-20^{\circ} \mathrm{C}$ to $+50^{\circ} \mathrm{C}$, relative humidity from $10 \%$ to $90 \%$ (for temperatures of dew-point from +5 to $+50^{\circ} \mathrm{C}$ ) and air flow rate from 0.15 to $1.0 \mathrm{~m} / \mathrm{s}$.

The verification of the mannequin reading correctness was carried out by multiple measurements of total heat insulating power of air gap close to the mannequin's skin under the same

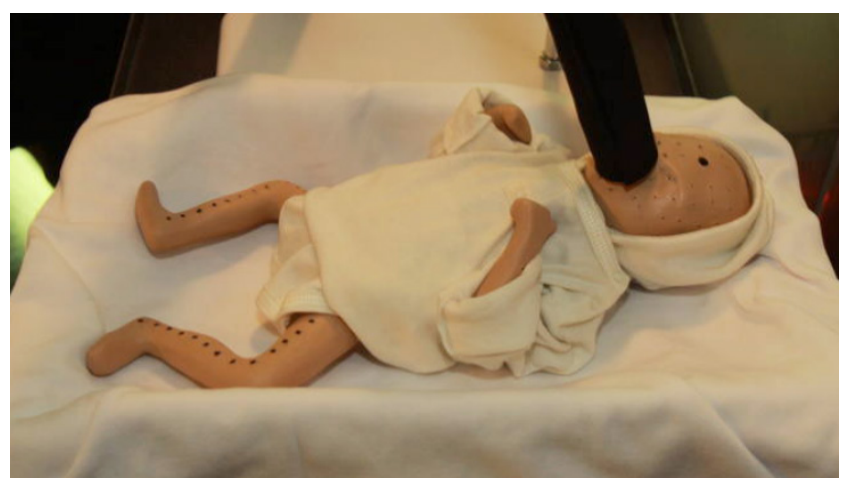

Fig. 4. Thermal mannequin of premature infant with the function of moisture secretion in its particular anatomic zones

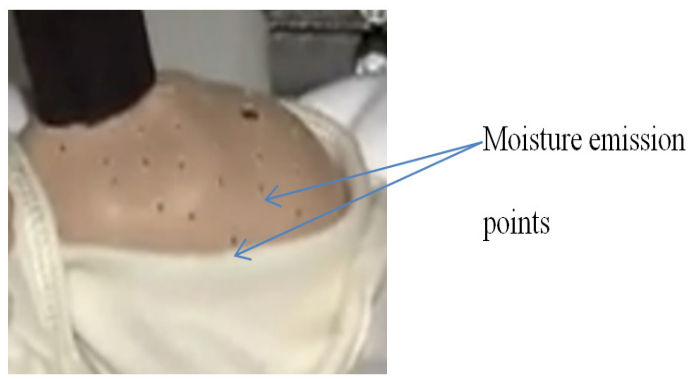

Fig. 5. Emission points of water located on the mannequin head

climatic conditions $\left(20^{\circ} \mathrm{C}, 25^{\circ} \mathrm{C}\right)$ and their comparison with those obtained for the commercially available mannequin called Newton produced by the Measurement Technology Northwest, USA. For that end, both mannequins were dismantled and located in a lying position in the large-size chamber to set the thermal conditions. The comparison of results is listed in Table 1. Moreover, the mannequin's surface temperature readings were checked in a computer and verified by means of external siliceous temperature sensors and Optris pyrometer to calibrate the measurement system.

The results of the total heat insulting power obtained were subjected to statistic assessment according to the standard PN-EN ISO 5725-2:2002 "Correctness of measuring method and measurement results - Part 2: Basic method for the determination of repeatability and reproducibility of the standard measurement method".
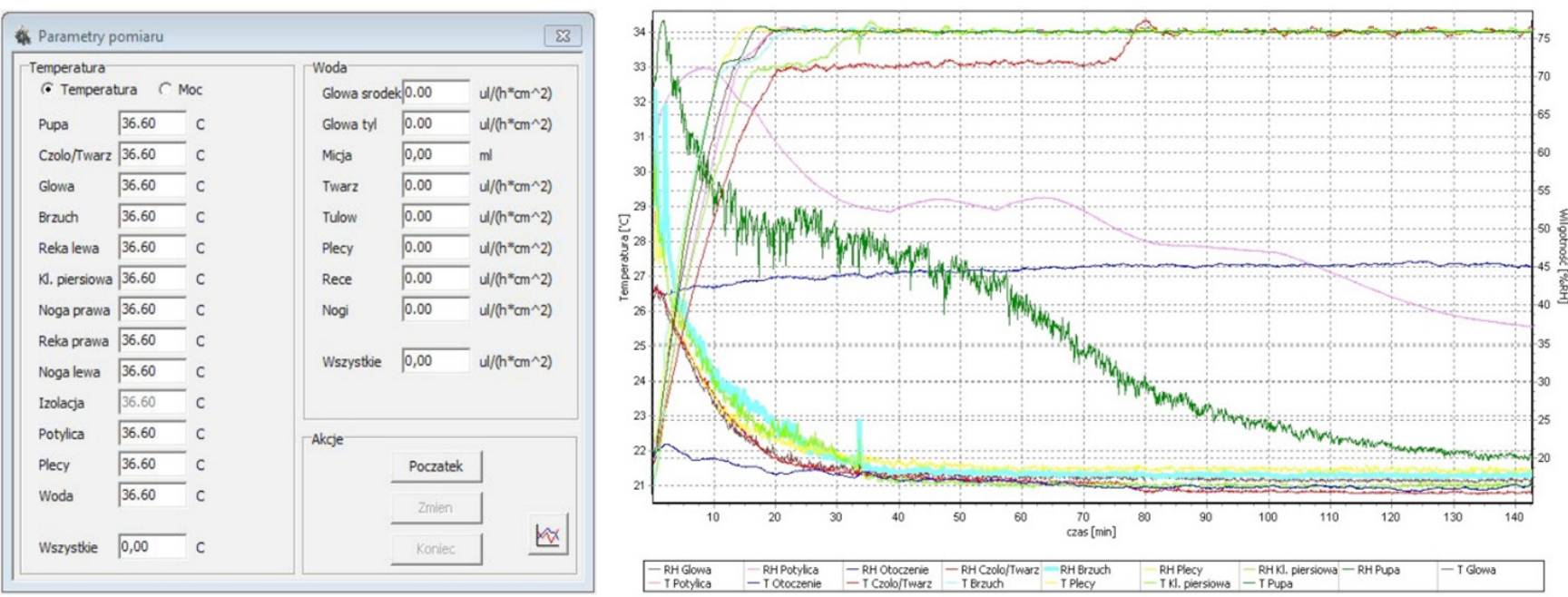

Fig. 6. Window of measurement parameters 
Table 1. Verification results of the readings correctness on the thermal mannequin together with evaluation of uncertainty

\begin{tabular}{|c|c|c|c|c|c|}
\hline \multirow{2}{*}{$\begin{array}{l}\text { Climatic } \\
\text { conditions }\end{array}$} & $\begin{array}{c}\text { Thermal } \\
\text { mannequin of } \\
\text { premature baby }\end{array}$ & $\begin{array}{l}\text { Newton thermal } \\
\text { mannequin }\end{array}$ & \multirow{2}{*}{$\begin{array}{l}\text { Temperature } \\
\text { readings in } \\
\text { the computer } \\
\text { program of } \\
\text { mannequin }\end{array}$} & \multirow{2}{*}{$\begin{array}{l}\text { Temperature } \\
\text { readings } \\
\text { on Optris } \\
\text { pyrometer }\end{array}$} & \multirow{2}{*}{$\begin{array}{c}\text { Temperature } \\
\text { readings on a } \\
\text { siliceous sensor }\end{array}$} \\
\hline & $\begin{array}{c}\text { Total heat } \\
\text { insulating power }\end{array}$ & $\begin{array}{c}\text { Total heat } \\
\text { insulating power }\end{array}$ & & & \\
\hline & $\mathrm{m}^{2} \cdot \mathrm{K} \cdot \mathrm{W}^{-1}$ & $\mathrm{~m}^{2} \cdot \mathrm{K} \cdot \mathrm{W}^{-1}$ & ${ }^{\circ} \mathrm{C}$ & ${ }^{\circ} \mathrm{C}$ & ${ }^{\circ} \mathrm{C}$ \\
\hline $20^{\circ} \mathrm{C} / 50 \%$ & $0.093 \pm 0.0005$ & $0.095 \pm 0.0006$ & 35.00 & 35.02 & 35.00 \\
\hline $25{ }^{\circ} \mathrm{C} / 50 \%$ & $0.098 \pm 0.0008$ & $0.099 \pm 0.0007$ & 35.00 & 34.98 & 35.01 \\
\hline
\end{tabular}

Table 2. List of statistics $\mathrm{W}$

\begin{tabular}{|c|c|c|}
\hline \multirow{2}{*}{$\begin{array}{c}\text { Climatic } \\
\text { conditions }\end{array}$} & Thermal mannequin of premature baby & Newton thermal mannequin \\
\cline { 2 - 3 } & Total heat insulating power & Total heat insulating power \\
\hline $200 \mathrm{C} / 50 \%$ & 0.872 & 0.826 \\
\hline $250 \mathrm{C} / 50 \%$ & 0.860 & 0.920 \\
\hline
\end{tabular}

Using Shapiro-Wilk's test, the conformity of distribution of total heat insulating power with the normal distribution was tested at a significance level of $\alpha=0.02$. Hypothesis $\mathrm{H} 0$ was put forward, confirming that the distribution of the feature tested is a normal distribution, compared with alternative hypothesis $\mathrm{H} 1$, stating that the distribution of the feature tested is different from the normal distribution. The value of statistics $\mathrm{W}$ was compared with the values of range between quantiles that in these tests amounted to < W(1/2a, n); $(W(1-1 / 2 \alpha, n)>$, that is, <0.743; $0.986>$. The values of statistics for the data are listed in Table 2.

The value of statistics $W$ in all the cases belongs to the range $<W(1 / 2 \alpha, n) ; W(1-1 / 2 \alpha, n)>$, which allows one to state that there is no basis at the significance level of $\alpha=0.02$ to reject the hypothesis $\mathrm{H} 0$, and the results obtained correspond to the normal distribution.

The differences between mean values obtained during the tests using both manikins were assessed using the Cochran - Cox test. This test assumes the null hypothesis $\mathrm{H} 0$ that there are no statistically significant differences between the mean values of the total heat insulating power. This hypothesis was verified against the $\mathrm{H} 1$ hypothesis, which predicates that the mean values are statistically different. If the calculated value of statistic $C$ does not belong to critical interval, the $\mathrm{HO}$ must be accepted. This test was carried out for the significance level of 0.02 . The critical interval is equal to $(-\infty ;-4.0321$ and $4.0321 ; \infty)$. The value of statistics $C$ was equal to 3.8508 for the tests performed under thermal conditions at $20 \circ \mathrm{C} / 50 \%$ and -1.3383 for the tests performed under thermal conditions at $250 \mathrm{C} / 50 \%$. As the results obtained do not belongs to the critical interval, it should be concluded that there are no statistically important differences between the results obtained on both thermal mannequins with significance level of 0.02 .

\section{Characteristics of the test fabrics}

The analysis of knitted fabrics used for the premature baby garments has shown that they are made of cotton yarns. Cotton knitted fabrics presently used as protective garments for premature babies can contribute to thermal discomfort, as with the evaporation of water absorbed from the baby's body and surroundings, the baby's body temperature goes down. Moreover, the moisture content decreases the heat insulating capability of the knitted fabric due to an increase in the coefficient of heat penetration. This discomfort increases when the premature baby is brought out from an incubator, where the ambient temperature is lower. The opinions about natural fibers, as particularly predestined for premature baby garments, can be undermined due to the following reasons. A high moisture (sweat) absorption causes excessive fiber swelling, adversely decreasing the size of skin pores. In extreme cases, these can be totally blocked, which results in unpleasant feelings connected with the garment sticking to body. At too high moisture absorption, as mentioned above, the garment heat insulating capability gets upset, which under unfavorable conditions, when organism itself produces little heat, causes unpleasant and in some circumstances "unhealthy" chill in the covered body part. With swollen fibers and consequently blocked air pores, the organism cannot take up more oxygen through skin. Supplying oxygen through skin plays a very important role in the organism physiology. Too much moisture directly under the garment can create favorable conditions for the development of microorganisms - bacteria and fungi, which is particularly dangerous for premature infants with a reduced resistance to the effect of microorganisms.

By using a two-layer structure of knitted fabric made with fibers with different affinities to moisture, it is possible to impart knitted fabrics with properties that would eliminate the above mentioned unfavorable phenomena. A typical two-layer structure of knitted fabrics consists of[20-27] (Fig.7):

- a layer of knitted fabric made of conductive-diffusive yarns that directly adhere to body. This layer takes off and transfers moisture from the body, in the form of both liquid and vapor phases.

- a layer of knitted fabric made of yarns with absorption properties. It does not directly come in contact with the skin. Its function is to keep moisture away from the body and evaporate it to surroundings. 


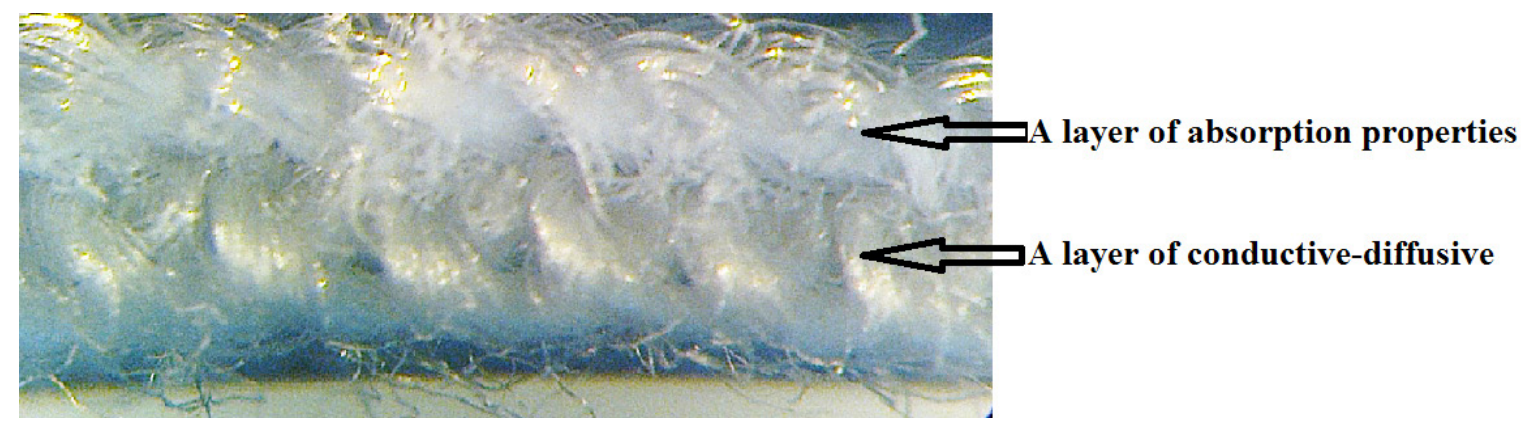

Fig. 7. Model of two-layer knitted fabric with required properties, made on the basis of a picture taken under an optical stereoscopic microscope[30]

Table 3. Yarns used to make the conductive-diffusive fabric layer[30]

\begin{tabular}{|c|c|c|}
\hline No. & Yarn type & Denotation \\
\hline 1. & Polypropylene $100 \%, 84$ dtex f $25 x 2$ & PP 84 dtex /f 25x2 \\
\hline 2. & Polyamide $66100 \%, 78 / 68$, looped, doubling number D=2 & PA66 78dtex/f68x2 \\
\hline 3. & Polyamide $66100 \%, 140$ dtex f 102, (Taslan) & PA66 140dtex/f102 (TASLAN) \\
\hline 4. & Polyester $100 \%, 167$ dtex f 96, (Torlen) & PES 167dtex/f96 (TORLEN) \\
\hline 5. & Polyester $100 \%$, microfibers, 150 dtex f 256 (Trewira) & PESTREVIRA 150dtex/f256x1 \\
\hline
\end{tabular}

Table 4. Yarns used to make the absorptive fabric layer[30]

\begin{tabular}{|c|c|c|}
\hline No. & Yarn types & Denotation \\
\hline 1. & Conventional cotton $100 \%, 20$ tex, $\alpha_{m}=90$ & CO 20 tex \\
\hline 2. & Conventional cotton $100 \%, 20$ tex, $\alpha_{m}=100$ & CO 20 tex \\
\hline 3. & Conventional cotton $100 \%, 20$ tex, $\alpha_{m}=121$ & CO 20 tex \\
\hline 4. & Organic cotton, combed $100 \%, 20$ tex, $\alpha_{m}=107$ & CO 20 tex \\
\hline 5. & Conventional cotton, combed $100 \%, 20$ tex, $\alpha_{m}=109$ & CO 20 tex \\
\hline 6. & Conventional cotton, combed bleached $100 \%, 20$ tex, $\alpha_{m}=111$ & CO 24 tex \\
\hline 7. & Conventional Cotton, combed bleached $100 \%, 15$ tex, $\alpha_{m}=100$ & CO BI 20tex \\
\hline 8. & Fibers made of wooden pulp $100 \%, 20$ tex, $\alpha_{m}=110$ & CO BI 15 tex \\
\hline 9. & Fibers made of bamboo pulp $100 \%, 20$ tex. $\alpha_{m}=129$ & Viscose 20 tex \\
\hline 10. & & Bamboo20tex \\
\hline
\end{tabular}

To fulfill the requirements of a two-layer knitted fabric, the following types of yarns with conductive-diffusive properties (described in [30]) were proposed:

The following types of yarns were used as yarns with absorptive properties:

The textile raw materials mentioned above were used to produce two-layer knitted fabrics composed of two plain stitches joined by the tucking technique with a polyamide textured thread with a low linear density PA 22dtexf7. The stitch structure is shown in Fig. 8.

For comparative purposes, two-layer knitted fabrics were also designed and produced with both layers made of the same raw materials. These fabrics are mentioned in Table 5 as variant 16 and 17 consisting of cotton yarns and variant 18 made of two layers of viscose yarn.
The two-layered knitted fabrics were made with the use of a cylindrical rib knitting machine from Mayer \& Cie Company, Type Oval 36, with the following characteristics: needle gauge $20 \mathrm{E}$, number of cam boxes $\mathrm{z}=36$, number of needles $\mathrm{I}=1872$, cylinder diameter $\varphi=30$ inches. During the production of twolayer knitted fabrics, the pretension value was $\mathrm{Fo}=0.1 \mathrm{cN} / \mathrm{tex}$, and the value of take-off power $\mathrm{F}_{\mathrm{A}}=0.2 \mathrm{cN} /$ wale.

Each of the produced knitted fabrics was tested to determine its surface weight according to the standard PN-EN 12127:2000, thickness according to the standard PN-EN ISO 5084:1999 and air permeability according to the standard PN-EN ISO 9237:1998. The tests results obtained are listed in Table 5.

For comparison purposes, the tests also included a commercial set of premature baby garment made of cotton knitted fabric with a surface weight of $277.17 \mathrm{~g} / \mathrm{m}^{2}$. 

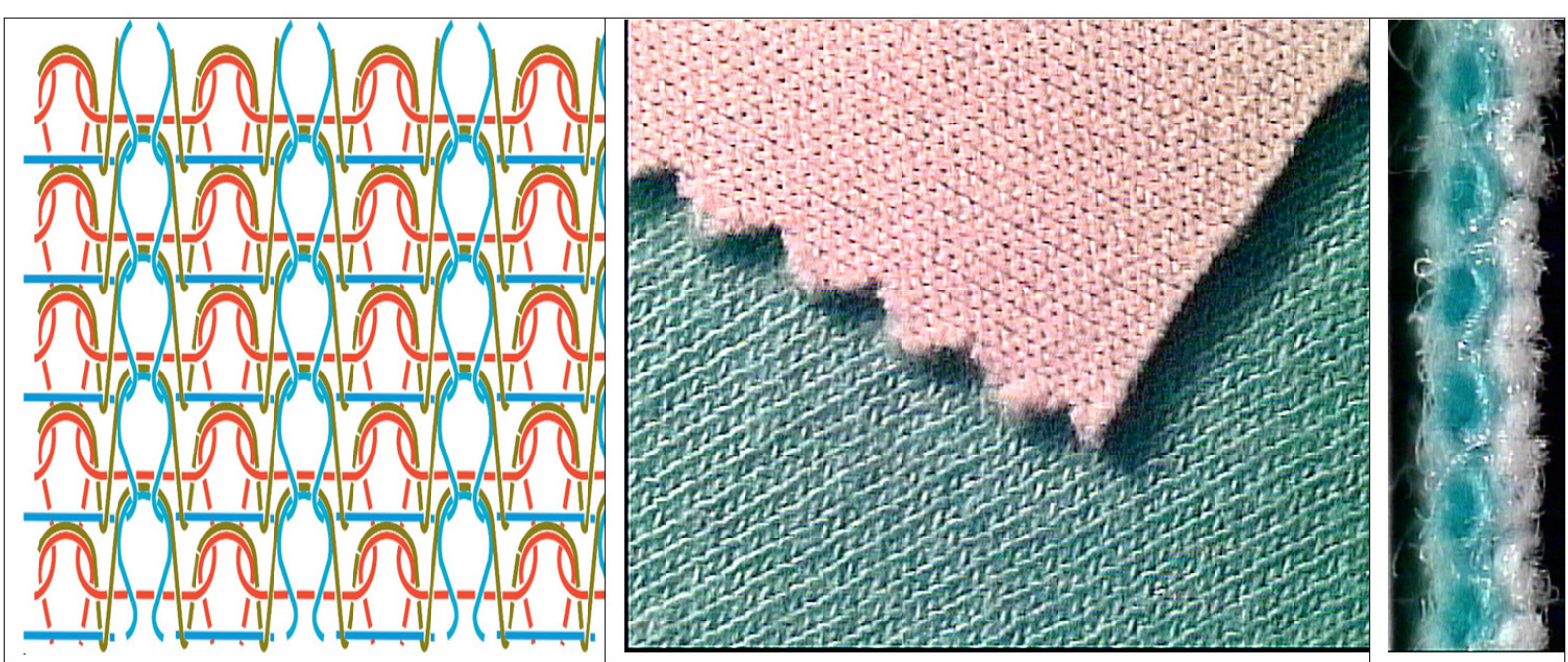

Fig. 8. Structure of two-layer knitted fabric and the view of conventional two-layer knitted fabric with its cross-section along the course Table 5. Test results of two-layer knitted fabrics[30]

\begin{tabular}{|c|c|c|c|c|c|}
\hline $\mathrm{Nr}$ & Type of fabric & $\begin{array}{l}\text { Surface } \\
\text { weight }\end{array}$ & Thickness & $\begin{array}{l}\text { Apparent } \\
\text { density }\end{array}$ & $\begin{array}{c}\text { Air } \\
\text { permeability }\end{array}$ \\
\hline & & $g \cdot m^{-2}$ & $\mathrm{~mm}$ & $\mathrm{~kg} \cdot \mathrm{m}^{-3}$ & $\mathrm{~mm} \cdot \mathrm{s}^{-1}$ \\
\hline 1 & $\begin{array}{l}\text { COBI20tex PP84dtex/ } \\
\text { f 25x2/PA66 22dtex/f7 }\end{array}$ & 225.05 & 1.42 & 158.49 & 491 \\
\hline 2 & $\begin{array}{l}\text { CO20tex PP84dtex/ } \\
\text { f 25x2/PA66 22dtex/f7 }\end{array}$ & 205.98 & 1.44 & 143.04 & 568 \\
\hline 3 & $\begin{array}{l}\text { CO24tex PP84dtex/ } \\
\text { f 25x2/PA66 22dtex/f7 }\end{array}$ & 235.22 & 1.61 & 146.10 & 403 \\
\hline 4 & $\begin{array}{l}\text { Bamboo 20tex PP84dtex/ } \\
\text { f 25x2/PA } 6622 \text { dtex/f7 white }\end{array}$ & 235.86 & 1.36 & 173.43 & 570 \\
\hline 5 & Viscose 20tex PP84dtex/f25x2/PA66 22dtex/f7 & 236.49 & 1.40 & 168.92 & 537 \\
\hline 6 & CO20tex PES 167dtex/f96/PA66 22dtex/f7 & 207.88 & 1.34 & 155.13 & 679 \\
\hline 7 & $\begin{array}{l}\text { CO BI 20tex PES167dtex/ } \\
\text { f 96/PA66 22dtex/f7 }\end{array}$ & 221.23 & 1.20 & 184.36 & 801 \\
\hline 8 & $\begin{array}{l}\text { CO BI 20tex PES TREVIRA 150dtex/f256x1/PA66 } \\
\text { 22dtex/f7 }\end{array}$ & 199.62 & 1.32 & 151.23 & 498 \\
\hline 9 & $\begin{array}{l}\text { CO24tex PES167dtex/ } \\
\text { f 96/PA66 22dtex/f7 }\end{array}$ & 219.96 & 1.27 & 173.20 & 675 \\
\hline 10 & Bamboo 20tex PES167dtex/f 96/PA6622dtex/f7 & 232.04 & 1.14 & 203.54 & 834 \\
\hline 11 & $\begin{array}{l}\text { Bamboo 20tex PES TREVIRA 150dtex/f256x1/PA66 } \\
\text { 22dtex/f7 }\end{array}$ & 221.87 & 1.29 & 171.99 & 527 \\
\hline 12 & Viscose 20tex PES 167dtex/f96/PA66 22dtex/f7 & 221.23 & 1.20 & 184.36 & 963 \\
\hline 13 & CO 20tex PA66 78dtex/f68x2/PA66 22dtex/f7 & 220.6 & 1.24 & 177.90 & 342 \\
\hline 14 & $\begin{array}{l}\text { CO BI 20tex PA66 140dtex/f102 (TASLAN)/PA } 66 \\
\text { 22dtex/f7 }\end{array}$ & 181.82 & 1.26 & 144.30 & 1130 \\
\hline 15 & $\begin{array}{l}\text { Bamboo } 20 \text { tex PA } 140 \text { dtex/ f102 TASLAN/ \ PA66 } 22 \\
\text { dtex/ f7 }\end{array}$ & 194.53 & 1.15 & 169.16 & 1550 \\
\hline 16 & CO BI 20tex CO BI 15tex/ PA66 22dtex/f7 & 191.35 & 1.18 & 162.16 & 992 \\
\hline 17 & CO24texCO 24tex/PA66 22dtex/f7 & 215.51 & 1.36 & 158.46 & 499 \\
\hline 18 & Viscose 20tex Viscose 20tex/ PA66 22dtex/f7 & 238.40 & 1.12 & 212.86 & 1080 \\
\hline
\end{tabular}


The tests were carried out at ambient temperature $\left(20^{\circ} \mathrm{C}\right)$ and a humidity of $50 \%$ with an air flow of $0.1 \mathrm{~m} / \mathrm{s}$, as it was established that these climatic conditions most often occur outside the incubator, under which a baby is most exposed to heat loss. For comparison, tests were also performed at a temperature of $35^{\circ} \mathrm{C}$, humidity of $65 \%$ and air flow of $0.1 \mathrm{~m} / \mathrm{s}$ to verify how a baby can feel in the incubator under set conditions in the standard garment set,.

A computer program controlled the heat stream value to maintain a constant temperature of $34^{\circ} \mathrm{C}$ in each mannequin zones. During measurements, the external conditions and the temperature of each zone were monitored. After establishing the set constant external conditions (temperature, humidity and air low rate) and the constant temperature values of each zone, there was always a constant value of heat stream. The assessment of the thermo-insulating properties of the garment was performed based on the analysis of the thermal parameters of the external environment, under-garment microclimate and parameters connected with the amount of emitted moisture, temperature and energy expenditure of the mannequin.

\section{Results and discussion}

On the basis of the parameters collected during measurements from the particular mannequin anatomic zones, the value of heat insulating capability of the infant garment set was calculated according to equation 1 :

$$
I_{a}=\frac{\left[\left(\sum_{i=1}^{n} f_{i} \cdot T_{s i}\right)-T_{a}\right] \cdot A}{\sum_{i=1}^{n} H_{c i}}, \frac{m^{2} \cdot K}{W}
$$

where:

$f_{i}-$ part of the total area constituting the area of $i$ zone,

$\mathrm{T}_{\mathrm{si}}$ - temperature of the surface of $i$ mannequin zone, ${ }^{\circ} \mathrm{C}$,

$\mathrm{T}_{\mathrm{a}}$ - ambient temperature ${ }^{\circ} \mathrm{C}$,

$\mathrm{A}$ - total mannequin area, $\mathrm{m}^{2}$,

$\mathrm{H}_{\mathrm{ci}}$ - heating power supplied to $i$ mannequin zones, W.[14]

Then, the effective heat insulating power was calculated from equation 2 :

$$
\mathrm{I}_{\mathrm{cle}}=\mathrm{I}_{\mathrm{ao}}-\mathrm{I}_{\mathrm{am}}, \frac{\mathrm{m}^{2} \cdot \mathrm{K}}{\mathrm{W}}
$$

where:

$\mathrm{I}_{\mathrm{ao}}$ - heat insulating capability of dressed mannequin,

$\mathrm{I}_{\mathrm{am}}$ - heat insulating power of nude mannequin.

On the basis of the parameters collected during measurements from the particular mannequin anatomic zones, the water vapor resistance value of the baby garment was calculated according to equation 3 :

$$
\mathrm{R}_{\mathrm{et}}=\frac{\left[\mathrm{P}_{\mathrm{si}}-\mathrm{P}_{\mathrm{a}}\right]}{\mathrm{Q} / \mathrm{A}-\left[\left(\mathrm{T}_{\mathrm{si}}-\mathrm{T}_{\mathrm{a}}\right) / \mathrm{R}_{\mathrm{ct}}\right.}, \frac{\mathrm{m}^{2} \cdot \mathrm{Pa}}{\mathrm{W}}
$$

where:

$\mathrm{P}_{\mathrm{si}}$ - water vapor pressure of $i$ mannequin zone, $\mathrm{Pa}$,

$\mathrm{P}_{\mathrm{a}}$ - water vapor pressure of environment, $\mathrm{Pa}$,
$\mathrm{Q} / \mathrm{A}$ - area weighted heat flux, $\mathrm{W} / \mathrm{m}^{2}$,

$\mathrm{R}_{\mathrm{ct}}$ - area weighted heat flux, $\left(\mathrm{W} / \mathrm{m}^{2}\right)^{2}$,

$\mathrm{T}_{\mathrm{si}}$ - zone average temperature, ${ }^{\circ} \mathrm{C}$,

$\mathrm{T}_{\mathrm{a}}$ - ambient temperature, ${ }^{\circ} \mathrm{C}[31]$.

Then, the effective water vapor resistance was calculated from equation 4:

$$
\mathrm{R}_{\mathrm{ef}}=\mathrm{R}_{\mathrm{et}}-\mathrm{R}_{\mathrm{et} 0}, \frac{\mathrm{m}^{2} \cdot \mathrm{Pa}}{\mathrm{W}}
$$

where:

$\mathrm{R}_{\mathrm{et}}$ - water vapor resistance of the dressed mannequin,

$\mathrm{R}_{\text {et0 }}$ - water vapor resistance of nude mannequin.

The effective heat insulating power and effective water vapor resistance were calculated with and without simulations of sweat secretion. The test results are presented in Table 6.

By means of Shapiro-Wilk's test, the conformity of the distribution of effective heat insulating power with simulation of sweat secretion to the normal distribution was confirmed.

Then, the single-factor analysis of variance ANOVA was performed, which showed that there are statistical differences between the mean values of the effective heat insulating power calculated with the sweat simulation of tested samples. For $\alpha=$ 0.05 , the value of test statistics calculated falls into the critical range defined by specified limits $[3.47 ; \infty)$. The successive stage of variance analysis was to find which averages differ between themselves (post-hoc tests). To that end, Tukey's test was carried out $(\alpha=0.05)$, making multiple comparisons by pairs, testing the difference between each pair of averages and generating a matrix where "+" indicated the acceptance of zero hypothesis, whereas "-" indicated its rejection in relation to alternative hypothesis. The results of Tukey's test are presented in Table 7.

The analysis of test results presented in Table 6 and in Figure 9 indicates that from the point of view of the final application, that is, protection premature babies before the hypothermia, the best effectiveness was obtained for the material variant of the garment called Bamboo 20tex PES TREVIRA 150dtex/f256x1/ PA66 22dtex/f7. The garment made of this kind of knitted fabric is characterized by the highest value of effective heat insulating power keeping the highest value of effective resistance of water vapor.

The next series of tests was oriented towards the evaluation of behavior of the selected material composition under different environmental conditions and the comparison of the biophysical properties of the newly developed fabrics with the commercial cotton baby garment. Ambient temperature was changed in the range of $20-350 \mathrm{C}$ and the relative humidity in a range of $50-65 \%$. Average values of the effective heat insulating power, calculated from 3 measurement repetitions are listed in Table 8 and shown in Figures 9 and 10. The results for dry mannequin (without sweat secretion) and for mannequin sweating with various intensities are also listed below. 
Table 6. Test results of heat insulating properties with the use of thermal mannequin together with evaluation of uncertainty

\begin{tabular}{|c|c|c|c|c|}
\hline No. & Fabric type & $\begin{array}{l}\text { Effective heat } \\
\text { insulating power }\end{array}$ & $\begin{array}{l}\text { Effective heat } \\
\text { insulating power }\end{array}$ & $\begin{array}{l}\text { Effective } \\
\text { resistance of } \\
\text { water vapor }\end{array}$ \\
\hline & & $\begin{array}{l}\text { No simulation of } \\
\text { sweat secretion }\end{array}$ & \multicolumn{2}{|c|}{$\begin{array}{l}\text { With simulation of sweat secretion - } \\
\qquad 3.2 \mathrm{ml} \cdot \mathrm{h}-1 \cdot \mathrm{cm}-2\end{array}$} \\
\hline & & $\mathrm{m} 2 \cdot \mathrm{K} \cdot \mathrm{W}-1$ & $\mathrm{~m} 2 \cdot \mathrm{K} \cdot \mathrm{W}-1$ & $\mathrm{~m} 2 \cdot \mathrm{Pa} \cdot \mathrm{W}-1$ \\
\hline 1 & $\begin{array}{l}\text { CO BI 20tex PP84dtex/ } \\
\text { f 25x2/PA66 22dtex/f7 }\end{array}$ & $0.099 \pm 0.0012$ & $0.060 \pm 0.0012$ & $15.987 \pm 0.5707$ \\
\hline 2 & $\begin{array}{l}\text { CO 20tex PP84dtex/ } \\
\text { f 25x2/PA66 22dtex/f7 }\end{array}$ & $0.093 \pm 0.0032$ & $0.059 \pm 0.0027$ & $19.411 \pm 0.2133$ \\
\hline 3 & $\begin{array}{l}\text { CO 24tex PP84dtex/ } \\
\text { f 25x2/PA66 22dtex/f7 }\end{array}$ & $0.102 \pm 0.0017$ & $0.055 \pm 0.0014$ & $21.099 \pm 0.5508$ \\
\hline 4 & $\begin{array}{l}\text { Bamboo 20tex PP84dtex/ } \\
\text { f25x2/ PA } 6622 \text { dtex/f7 white }\end{array}$ & $0.096 \pm 0.0012$ & $0.056 \pm 0.0008$ & $16.455 \pm 0.2021$ \\
\hline 5 & Viscose 20tex PP84dtex/f25x2/ PA66 22dtex/f7 & $0.101 \pm 0.0017$ & $0.059 \pm 0.0012$ & $16.911 \pm 0.1221$ \\
\hline 6 & $\begin{array}{l}\text { CO 20tex PES 167dtex/f96/ } \\
\text { PA66 22dtex/f7 }\end{array}$ & $0.088 \pm 0.0017$ & $0.037 \pm 0.0049$ & $16.002 \pm 0.1339$ \\
\hline 7 & $\begin{array}{l}\text { CO BI 20tex PES167dtex/ } \\
\text { f96/PA66 22dtex/f7 }\end{array}$ & $0.092 \pm 0.0024$ & $0.047 \pm 0.0044$ & $15.596 \pm 0.1712$ \\
\hline 8 & $\begin{array}{l}\text { CO BI 20tex PES TREVIRA 150dtex/f256x1/PA66 } \\
\text { 22dtex/f7 }\end{array}$ & $0.095 \pm 0.0012$ & $0.061 \pm 0.0017$ & $20.081 \pm 0.0491$ \\
\hline 9 & $\begin{array}{l}\text { CO 24tex PES167dtex/ } \\
\text { f96/PA66 22dtex/f7 }\end{array}$ & $0.092 \pm 0.0017$ & $0.061 \pm 0.0014$ & $18.226 \pm 0.0672$ \\
\hline 10 & $\begin{array}{l}\text { Bamboo 20tex PES167dtex/ } \\
\text { f96/PA6622dtex/f7 }\end{array}$ & $0.089 \pm 0.0012$ & $0.059 \pm 0.0032$ & $18.501 \pm 0.2315$ \\
\hline 11 & $\begin{array}{l}\text { Bamboo 20tex PES TREVIRA 150dtex/f256x1/PA66 } \\
\text { 22dtex/f7 }\end{array}$ & $0.094 \pm 0.0027$ & $0.065 \pm 0.0014$ & $22.769 \pm 0.7047$ \\
\hline 12 & Viscose 20tex PES 167dtex/f96/ PA66 22dtex/f7 & $0.108 \pm 0.0008$ & $0.058 \pm 0.0038$ & $18.614 \pm 0.2156$ \\
\hline 13 & CO 20tex PA66 78dtex/f68x2/ PA66 22dtex /f7 & $0.080 \pm 0.0019$ & $0.065 \pm 0.0022$ & $19.463 \pm 0.3256$ \\
\hline 14 & $\begin{array}{l}\text { CO BI20tex PA66 140dtex/f102 (TASLAN)/PA } 66 \\
\text { 22dtex/f7 }\end{array}$ & $0.085 \pm 0.0030$ & $0.044 \pm 0.0017$ & $19.442 \pm 0.2629$ \\
\hline 15 & $\begin{array}{l}\text { Bamboo } 20 \text { tex PA } 140 \text { dtex/f102 TASLAN/ \PA66 } 22 \\
\text { dtex/ f7 }\end{array}$ & $0.101 \pm 0.0022$ & $0.059 \pm 0.0055$ & $16.133 \pm 0.0768$ \\
\hline 16 & CO BI20tex CO BI 15tex/PA66 22dtex/f7 & $0.086 \pm 0.0038$ & $0.047 \pm 0.0008$ & $15.170 \pm 0.1059$ \\
\hline 17 & CO24texCO24tex/PA66 22dtex/f7 & $0.081 \pm 0.0012$ & $0.040 \pm 0.0012$ & $17.999 \pm 0.5713$ \\
\hline 18 & Viscose 20texViscose 20tex/ PA66 22dtex/f7 & $0.096 \pm 0.0019$ & $0.053 \pm 0.032$ & $16.049 \pm 0.0222$ \\
\hline
\end{tabular}


Table 7. Matrix of the comparison results of effective heat insulating power with simulation of sweat secretion by Tukey's test (the numeric denotation of samples is compatible with those in Table 6)

\begin{tabular}{|c|c|c|c|c|c|c|c|c|c|c|c|c|c|c|c|c|c|c|}
\hline & 1 & 2 & 3 & 4 & 5 & 6 & 7 & 8 & 9 & 10 & 11 & 12 & 13 & 14 & 15 & 16 & 17 & 18 \\
\hline 1 & & + & + & + & + & - & + & + & + & + & + & + & - & - & + & - & - & + \\
\hline 2 & + & & + & + & + & + & + & + & + & + & + & - & - & + & + & + & - & + \\
\hline 3 & + & + & & + & + & - & + & + & + & - & + & + & - & - & + & - & - & + \\
\hline 4 & + & + & + & & + & + & + & + & + & + & + & - & - & - & + & + & - & + \\
\hline 5 & + & + & + & + & & - & + & + & + & - & + & + & - & - & + & - & - & + \\
\hline 6 & - & + & - & + & - & & + & + & + & + & + & - & + & + & - & + & + & + \\
\hline 7 & + & + & + & + & + & + & & + & + & + & + & - & - & + & + & + & - & + \\
\hline 8 & + & + & + & + & + & + & + & & + & + & + & - & - & + & + & + & - & + \\
\hline 9 & + & + & + & + & + & + & + & + & & + & + & - & - & + & + & + & - & + \\
\hline 10 & + & + & - & + & - & + & + & + & + & & + & - & + & + & - & + & + & + \\
\hline 12 & + & - & + & - & + & - & - & - & - & - & - & & - & - & + & - & - & - \\
\hline 13 & - & - & - & - & - & + & - & - & - & + & - & - & & + & - & + & + & - \\
\hline 14 & - & + & - & - & - & + & + & + & + & + & + & - & + & & - & + & + & - \\
\hline 15 & + & + & + & + & + & - & + & + & + & - & + & + & - & - & & - & - & + \\
\hline 16 & - & + & - & + & - & + & + & + & + & + & + & - & + & + & - & & + & + \\
\hline 17 & - & - & - & - & - & + & - & - & - & + & - & - & + & + & - & + & & - \\
\hline 18 & + & + & + & + & + & + & + & + & + & + & + & - & - & - & + & + & - & \\
\hline
\end{tabular}

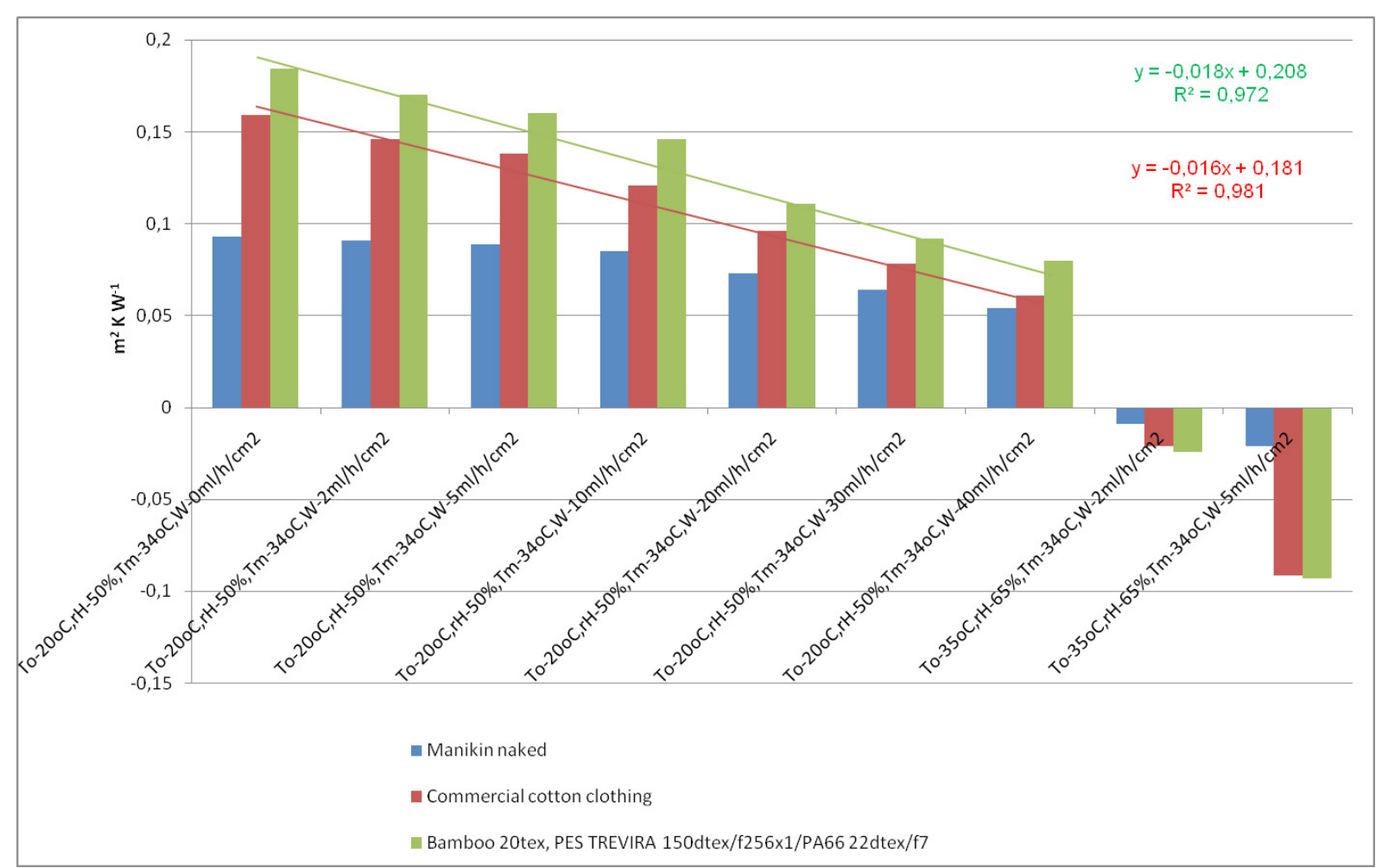

Fig. 9. List of test results of total heat insulating power measured on thermal mannequin 


\begin{tabular}{|c|c|c|c|c|c|c|c|c|c|c|c|c|c|c|c|c|}
\hline 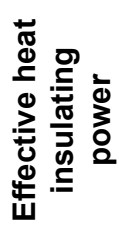 & $\begin{array}{l}\bar{y} \\
\dot{y} \\
\dot{y} \\
\dot{d} \\
\xi\end{array}$ & & $\begin{array}{l}\infty \\
\varnothing \\
0 \\
0 \\
+1 \\
0 \\
0 \\
0 \\
0\end{array}$ & 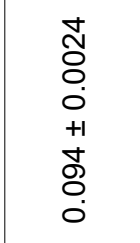 & & $\begin{array}{l}0 \\
0 \\
8 \\
0 \\
+1 \\
10 \\
0 \\
0 \\
0\end{array}$ & $\begin{array}{l}\overline{\widehat{\sigma}} \\
0 \\
0 \\
+1 \\
o \\
o \\
0 \\
0\end{array}$ & & $\begin{array}{l}+ \\
\dot{8} \\
0 \\
+1 \\
+ \\
0 \\
0 \\
0\end{array}$ & $\begin{array}{l}\frac{0}{\delta} \\
8 \\
0 \\
+1 \\
+ \\
0 \\
0\end{array}$ & & $\begin{array}{l}5 \\
\overline{8} \\
0 \\
+1 \\
0 \\
0 \\
0 \\
0\end{array}$ & $\begin{array}{l}\hat{\delta} \\
\dot{8} \\
0 \\
+1 \\
\overline{8} \\
0\end{array}$ & & 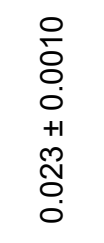 & $\begin{array}{l}\stackrel{N}{\grave{Q}} \\
\dot{0} \\
\dot{0} \\
+1 \\
\infty \\
0 \\
0 \\
0\end{array}$ \\
\hline 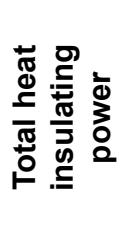 & $\begin{array}{l}\bar{y} \\
\dot{z} \\
\dot{y} \\
\dot{d} \\
\xi\end{array}$ & 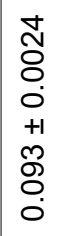 & 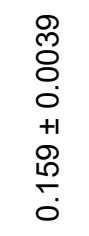 & $\begin{array}{l}10 \\
0 \\
0 \\
0 \\
+1 \\
+1 \\
0 \\
0 \\
0\end{array}$ & 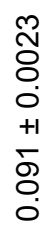 & $\begin{array}{l}0 \\
\mathscr{O} \\
0 \\
0 \\
+1 \\
+ \\
0 \\
+ \\
\dot{0}\end{array}$ & \begin{tabular}{l}
\multirow{2}{*}{} \\
8 \\
0 \\
0 \\
+1 \\
$\stackrel{+}{0}$ \\
$\dot{0}$
\end{tabular} & 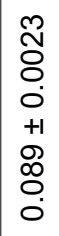 & $\begin{array}{l}\text { के } \\
\delta \\
0 \\
+1 \\
+1 \\
0 \\
\stackrel{m}{0} \\
0\end{array}$ & $\begin{array}{l}\text { क् } \\
8 \\
0 \\
+1 \\
0 \\
\vdots \\
0\end{array}$ & \begin{tabular}{l}
\multirow{2}{*}{} \\
8 \\
0 \\
+1 \\
+1 \\
0 \\
0 \\
0 \\
0
\end{tabular} & 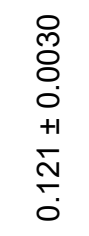 & $\begin{array}{l}0 \\
\tilde{O} \\
0 \\
0 \\
+1 \\
0 \\
0 \\
\dot{0} \\
0\end{array}$ & $\begin{array}{l}0 \\
\bar{\delta} \\
0 \\
0 \\
+1 \\
0 \\
0 \\
0 \\
0\end{array}$ & $\begin{array}{l}\stackrel{1}{0} \\
\delta \\
0 \\
0 \\
+1 \\
0 \\
0 \\
0 \\
0\end{array}$ & 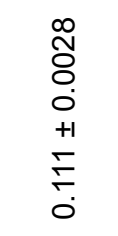 \\
\hline 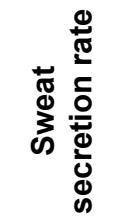 & $\frac{\underline{\tilde{E}}}{\frac{\tilde{U}}{\underline{z}}}$ & \multicolumn{3}{|c|}{0} & \multicolumn{3}{|c|}{$N$} & \multicolumn{3}{|c|}{ م } & \multicolumn{3}{|c|}{ 으 } & \multicolumn{3}{|c|}{ ํ } \\
\hline 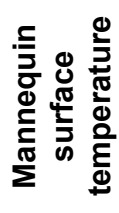 & 0 & \multicolumn{3}{|c|}{ ల్ల } & \multicolumn{3}{|c|}{ ले } & \multicolumn{3}{|c|}{ স্ল } & \multicolumn{3}{|c|}{ ఉా } & \multicolumn{3}{|c|}{ ङे } \\
\hline 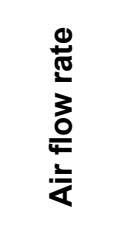 & $\frac{\infty}{\xi}$ & \multicolumn{3}{|c|}{$\bar{\sigma}$} & \multicolumn{3}{|c|}{$\bar{o}$} & \multicolumn{3}{|c|}{$\bar{\sigma}$} & \multicolumn{3}{|c|}{$\bar{o}$} & \multicolumn{3}{|c|}{$\bar{o}$} \\
\hline 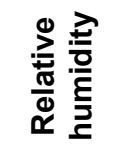 & ¿̊ & \multicolumn{3}{|c|}{ i } & \multicolumn{3}{|c|}{ 유 } & \multicolumn{3}{|c|}{ in } & \multicolumn{3}{|c|}{ 오 } & \multicolumn{3}{|c|}{ 유 } \\
\hline 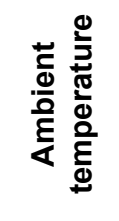 & 0 & \multicolumn{3}{|c|}{ 尺 } & \multicolumn{3}{|c|}{ 尺 } & \multicolumn{3}{|c|}{ 尺 } & \multicolumn{3}{|c|}{ 尺 } & \multicolumn{3}{|c|}{ 尺 } \\
\hline 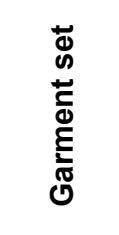 & & & \multicolumn{2}{|c|}{ 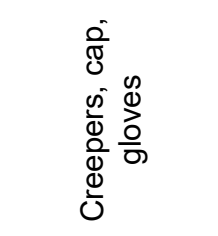 } & & \multicolumn{2}{|c|}{ 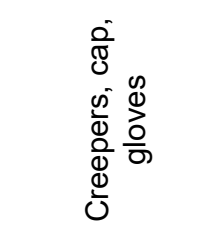 } & \multicolumn{3}{|c|}{ 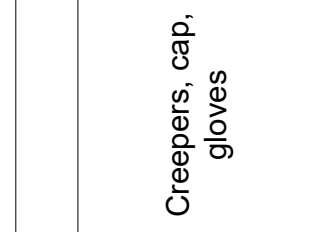 } & \multicolumn{3}{|c|}{ 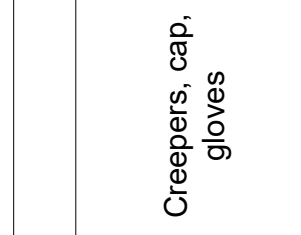 } & & \multicolumn{2}{|c|}{ 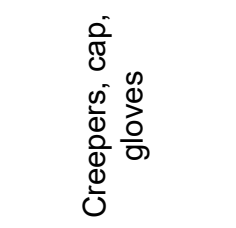 } \\
\hline 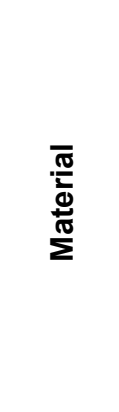 & & 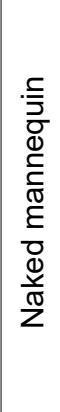 & 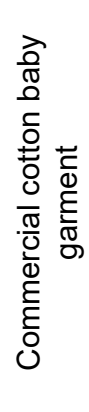 & 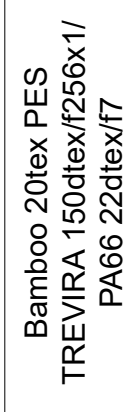 & 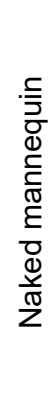 & 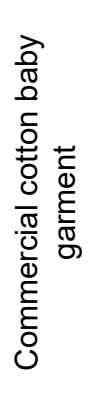 & 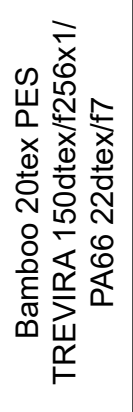 & 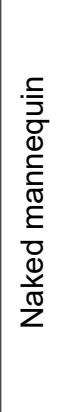 & 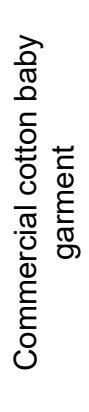 & 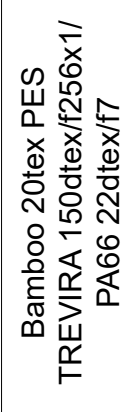 & 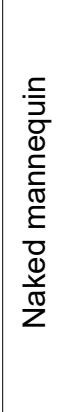 & 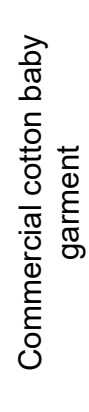 & 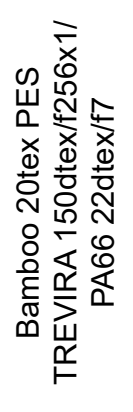 & 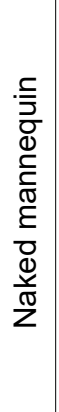 & 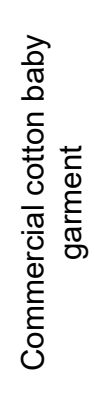 & 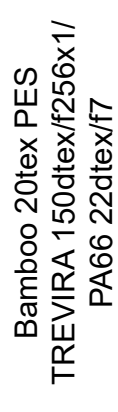 \\
\hline
\end{tabular}




\begin{tabular}{|c|c|c|c|c|c|c|c|c|c|c|c|c|c|}
\hline 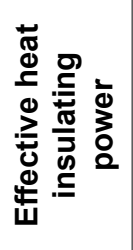 & $\begin{array}{l}\bar{s} \\
\dot{s} \\
\dot{y} \\
\dot{\sim} \\
\xi\end{array}$ & & $\begin{array}{l}8 \\
8 \\
8 \\
0 \\
+1 \\
+ \\
\vdots \\
0 \\
0\end{array}$ & 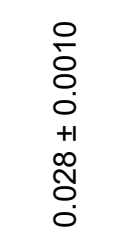 & & $\begin{array}{l}\infty \\
0 \\
8 \\
0 \\
+1 \\
\text { i } \\
0 \\
0\end{array}$ & $\begin{array}{l}0 \\
8 \\
0 \\
0 \\
+1 \\
0 \\
0 \\
0 \\
0\end{array}$ & & 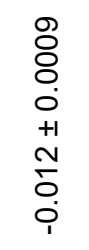 & $\begin{array}{l}8 \\
0 \\
0 \\
0 \\
+1 \\
+1 \\
0 \\
0 \\
0\end{array}$ & & $\begin{array}{l}0 \\
\vdots \\
0 \\
0 \\
+1 \\
0 \\
0 \\
0 \\
0 \\
1\end{array}$ & 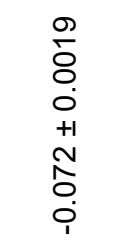 \\
\hline 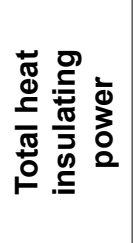 & 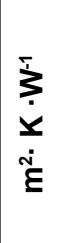 & $\begin{array}{l}0 \\
0 \\
0 \\
+1 \\
+ \\
0 \\
0 \\
0\end{array}$ & $\begin{array}{l}\bar{̃} \\
8 \\
0 \\
+1 \\
\infty \\
0 \\
0 \\
0\end{array}$ & 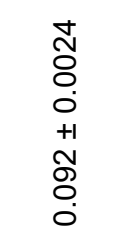 & 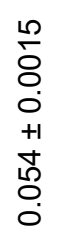 & $\begin{array}{l}\hat{0} \\
\delta \\
0 \\
+1 \\
\dot{8} \\
0 \\
0\end{array}$ & $\begin{array}{l}\bar{\delta} \\
0 \\
0 \\
+1 \\
0 \\
0 \\
0 \\
0\end{array}$ & $\begin{array}{l}\infty \\
0 \\
8 \\
0 \\
0 \\
+1 \\
8 \\
0 \\
0 \\
0 \\
1\end{array}$ & $\begin{array}{l}8 \\
8 \\
8 \\
0 \\
+1 \\
+\overline{0} \\
0 \\
0 \\
i\end{array}$ & $\begin{array}{l}0 \\
0 \\
0 \\
0 \\
+1 \\
+1 \\
0 \\
0 \\
i\end{array}$ & $\begin{array}{c}8 \\
8 \\
0 \\
0 \\
+1 \\
+1 \\
\grave{0} \\
0 \\
\dot{1}\end{array}$ & 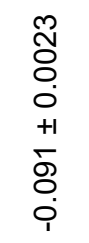 & 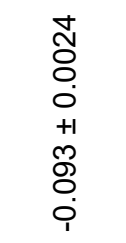 \\
\hline 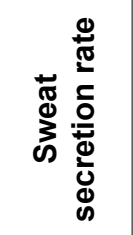 & 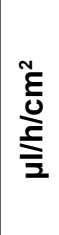 & & \multicolumn{2}{|l|}{ ஓి } & \multicolumn{3}{|c|}{ 우 } & \multicolumn{3}{|c|}{$\sim$} & \multicolumn{3}{|c|}{ ما } \\
\hline 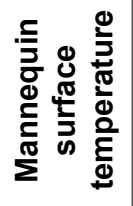 & 0 & & \multicolumn{2}{|l|}{ ङे } & \multicolumn{3}{|c|}{ "ా } & \multicolumn{3}{|c|}{ ఉે } & \multicolumn{3}{|c|}{ फे } \\
\hline $\begin{array}{l}\frac{1}{0} \\
\frac{\pi}{5} \\
3 \\
\frac{0}{4} \\
\frac{1}{4}\end{array}$ & $\stackrel{\infty}{\xi}$ & & \multicolumn{2}{|l|}{$\overline{0}$} & \multicolumn{3}{|c|}{ ¿. } & \multicolumn{3}{|c|}{$\check{o}$} & \multicolumn{3}{|c|}{$\check{o}$} \\
\hline 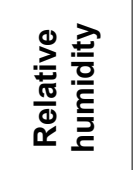 & ¿̊ & & \multicolumn{2}{|l|}{ 오 } & \multicolumn{3}{|c|}{ 요 } & \multicolumn{3}{|c|}{ 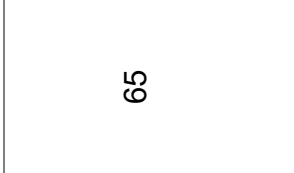 } & \multicolumn{3}{|c|}{$\stackrel{10}{0}$} \\
\hline 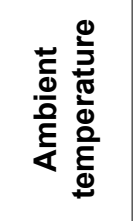 & 0 & & \multicolumn{2}{|l|}{ ㄱ } & \multicolumn{3}{|c|}{ 尺 } & \multicolumn{3}{|c|}{ 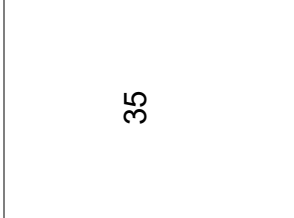 } & \multicolumn{3}{|c|}{ 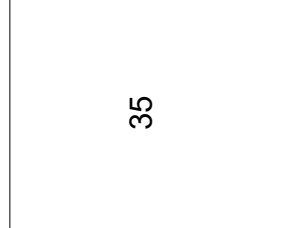 } \\
\hline 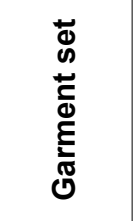 & & & \multicolumn{2}{|c|}{ 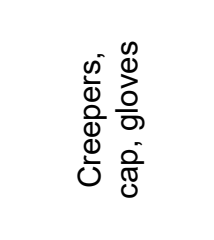 } & & \multicolumn{2}{|c|}{ 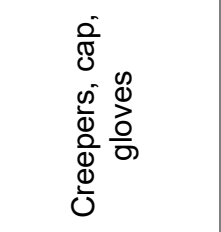 } & \multicolumn{3}{|c|}{ 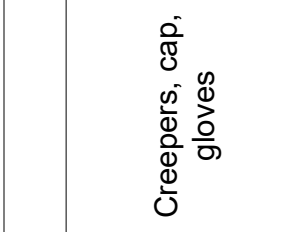 } & & \multicolumn{2}{|c|}{ 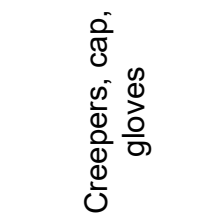 } \\
\hline $\begin{array}{l}\bar{\pi} \\
\frac{\pi}{\bar{N}} \\
\overline{\frac{\pi}{\Sigma}}\end{array}$ & & 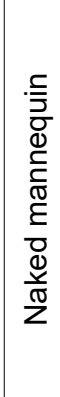 & 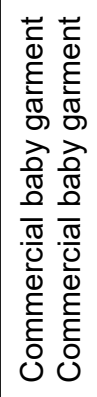 & 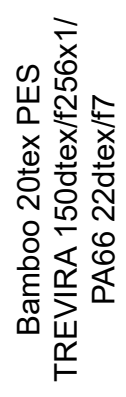 & 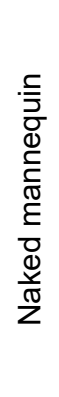 & 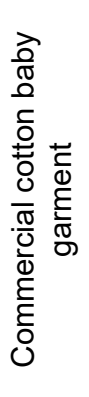 & 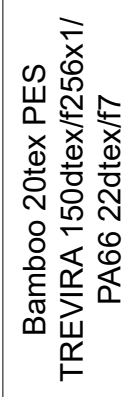 & 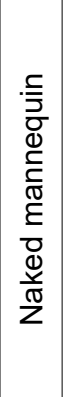 & 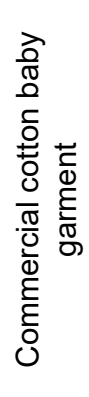 & 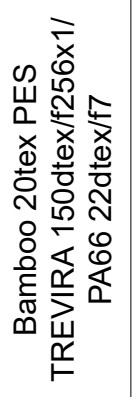 & 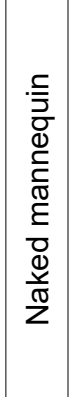 & 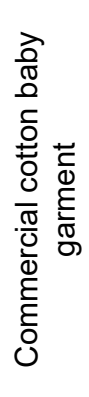 & 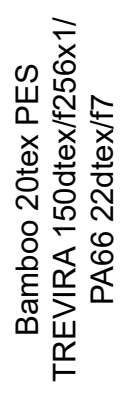 \\
\hline
\end{tabular}




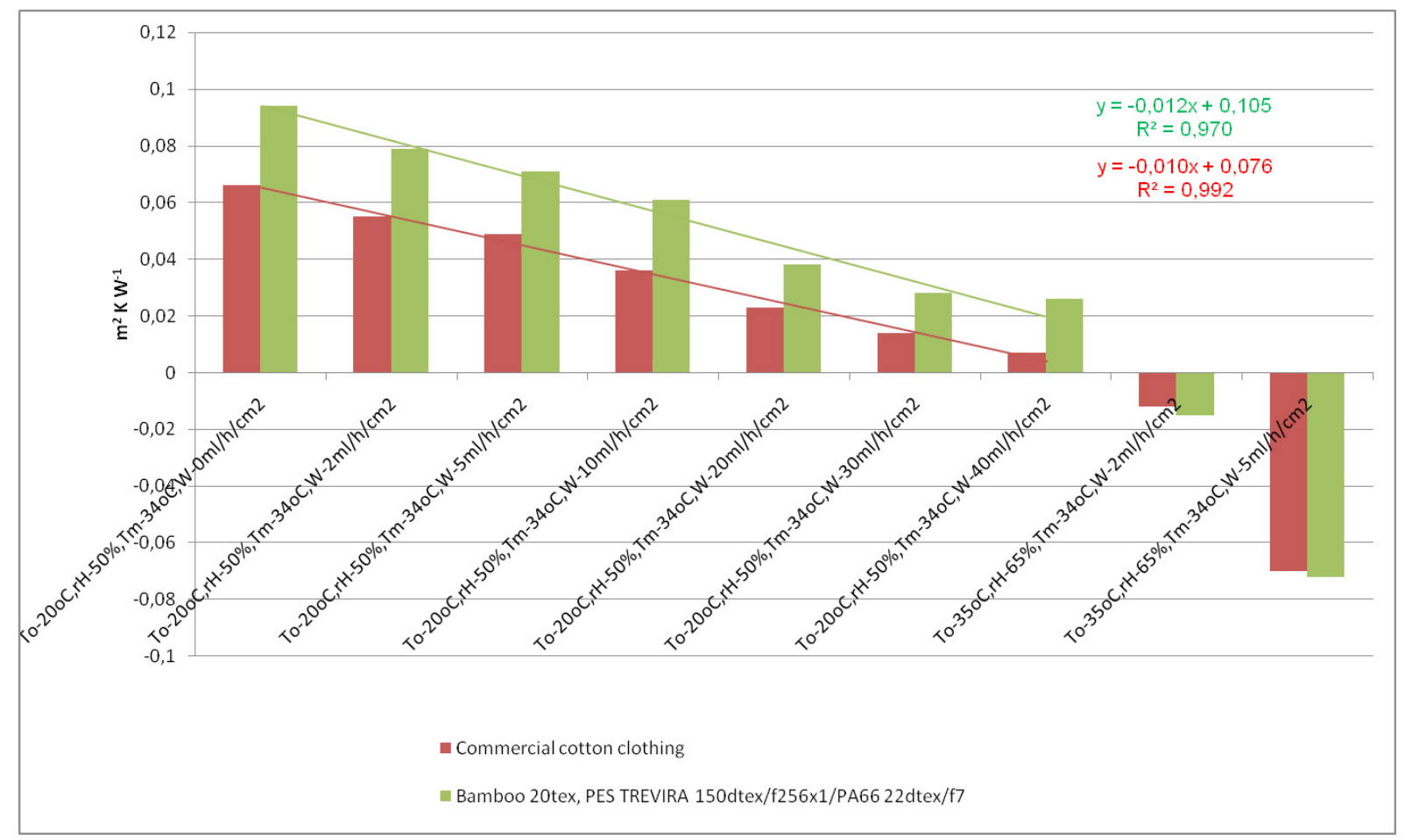

Fig.10. List of test results of effective heat insulating power measured on thermal mannequin

From the analysis of the data presented in Fig. 10, it follows that the effective heat insulating power of the baby garment made of bamboo/PES knitted fabric (Bamboo 20tex PES TREVIRA 150dtex/f256x1/PA66 22dtex/f7/) is higher by $42.4 \%$ from that of the commercial baby garment made of cotton knitted fabric, when tested without sweat simulation. When the simulated sweating is at a level of $10 \mu \mathrm{l} / \mathrm{h} / \mathrm{cm}^{2}$, the difference between the garments tested increases to $69.44 \%$, while with the intensity of sweating at a level of $40 \mu \mathrm{l} / \mathrm{h} / \mathrm{cm}^{2}$, this difference increases to $271.42 \%$.

The sweating intensity of mannequin refers to the literature reports that describe that babies born at the proper time secrete about $2 \mu \mathrm{l} / \mathrm{h} / \mathrm{cm}^{2}$ of sweat, babies born after 34 weeks of pregnancy secrete from 5 to $20 \mu \mathrm{l} / \mathrm{h} / \mathrm{cm}^{2}$ of sweat and babies born before the 30th week of pregnancy had water loss even at a level of $32 \mu \mathrm{l} / \mathrm{h} / \mathrm{cm}^{2}$.[26,27]

Analyzing the test results, it can be observed that an increase in the moisture/sweat secretion rate causes a decrease in the heat insulating power of the baby garment set tested. As shown in Figs 9 and 10, the rate of decreasing effective heat insulating power is similar for both types of materials used. The tangent of trend line for cotton clothing is equal to -0.010 and for newly developed material composition takes the value of-0.012. Based on the tests performed, it was observed that the author's solution of baby garments better protects the baby's body against heat loss than the commercial garments.

In the case of the two final measurements, the result of heat insulating power was negative as the heat flux was supplied from outside to the baby mannequin. One can believe that a baby staying under such conditions would be overheated. Consequently, there can occur a dilation of fine peripheral vessels located in the skin. Through dilated vessels, the excess heat is then given back to the environment by convection or with sweat.

\section{Summarizing}

The neonate mannequin with the function of moisture secretion in its particular anatomic zones allows one to determine the heat insulating power parameters of infantile clothing under the simulation of the real conditions of use. It is the only phantom worldwide making it possible to provide such a wide measurement range, allowing better understanding of the heat losses in the premature baby's body through convection, conduction, evaporation and radiation.

The premature baby mannequin presented in this paper makes it possible in future to optimize thermal conditions in incubators department of neonatology and to analyze the clothing used for infants. Owing to this mannequin, it was possible to conduct studies connected with the development of the new generation of protective clothing for premature babies characterized by a much higher value of effective heat insulating power at different rate of sweat secretion comparing to the commercially available cotton garment.

\section{Acknowledgment}

The studies were carried out and the mannequin was made within the OPUS project: "Optimization of the protective garment structure for premature infants with the use of original tools supporting the designing process" No. UMO201103BST806275 financed by the National Center of Science in Krakow. 


\section{References}

[1] M. Baumert, A. Łukomska, Ł. Krzych, J. Magnucki, M. Pacula, Zaburzenia w okresie adaptacyjnym noworodków urodzonych "blisko terminu porodu". Ginekologia Polska, 2011, 82, 119-125

[2] M.Davidoff, T.Dias, K.Damus, et al. Changes in the gestational age distribution among U.S. Singelton birth: impact on rates of late preterm birth, 1992 to 2002. Seminars in Perinatology, 2006, 30, 8-15.

[3] E.J. Holland, C.A. Wilson, R.M. Laing, B.E. Niven. Microclimate ventilation of infant bedding, International Journal of Clothing Science and Technology. 1999, 11, 4, $226-239$

[4] C.A. Wilson, R.M. Laing, T. Tamura. Intrinsic "dry" thermal resistance of dry infant bedding during use: Part 2: estimated vs measured, International Journal of Clothing Science and Technology. 2004, 16, 3, $310-323$

[5] O. K. Helder, P. Mulder, J.B. van Goudoever. ComputerGenerated Versus Nurse-Determined Strategy for Incubator Humidity and Time to Regain Birthweight. Journal of Obstetric, Gynecologic, \& Neonatal Nursing, 2008, 37, 255-261.

[6] T.I. Sherman, J.S. Greenspan, N. St Clair, S.M. Touch, T.H. Shaffer. Optimizing the Neonatal Thermal Environment. Neonatal Network, 2006, 25, 4, 251-60.

[7] K. Fairchild, D. Sokora, J. Scott, S. Zanelli. Therapeutic hypothermia on neonatal transport: 4-year experience in a single NICU. Journal of Perinatology, 2010, 30, 5, 324329.

[8] M. Vento, P.Y. Cheung, M. Aguar. The first golden minutes of the extremely-low-gestational-age neonate: a gentle approach. Neonatology, 2009, 95, 4, 286-298.

[9] E.D. Bowman, R.N.D. Roy. Control of temperature during newborn transport: an old problem with new difficulties. Journal of Pediatrics and Child Health, 1997, 33, 5, 398401.

[10] M. E Anderson, T.A. Longhofer, W. Philips, D.E. McRay. Passive cooling to initiate hypothermia for transported encephalopathy newborns. Journal of Perinatology, 2007, 27,9, 592-593.

[11] B. Agourram, V. Bach, P. Tourneux, G. Krim, S. Delnaud, J. P. Libert. Why wrapping premature neonates to prevent hypothermia can predispose to overheating, Journal of Applied Physiology, 108, 1674 - 1681, 2010.

[12] Anonymous. EN ISO 7933. Ergonomics of thermal environment - Analytical determination and interpretation of heat stress using calculation of the predicted heat strain. European Committee for Standardization, Brussels, 2004.

[13] E.B. Elabbassi, K. Chardon, V. Bach , F. Telliez, S. Delanaud, J.P. Libert. Head insulation and heat loss in naked and clothed newborns using a thermal mannequin. Medical Physics, 2002, 29, 6, 1090-1096.

[14] PN-ENISO 15831:2006, Odzież - Właściwości fizjologiczne - Pomiar izolacyjności cieplnej z zastosowaniem manekina termicznego.

[15] D. Bolin, I. Holmer, I. Sarman, R. Tunell. The use of an "infant thermal manikin" for the assessment of different neonatal heating equipments for premature newborn babies. Physiological Models, IEEE Engineering in Medicine and Biology Society, 11th Annual International Conference, 1989, 0252-0253.
[16] Anonymous. ISO 7726:2002. Ergonomics of the thermal environment - Instruments for measuring physical quantities. 2002.

[17] R. Korycki. Local Optimization of Bonnet Thickness in Global Heat Balance of Neonate. Fibres \& Textiles in Eastern Europe, 2017, 25, 1(121), 81-88.

[18] E.B. Elabbassi, K. Belghazi, S. Delanaud, J.P. Libert. Dry heat loss in incubator: comparison of two premature newborn sized manikins. European Journal of Applied Physiology, 2004, 92, 6, 679-682.

[19] Z. Ostrowski, M. Rojczyk, J. Łaszczyk, I. Szczygieł, J. Kaczmarczyk, A. J.Nowak. Infant care bed natural convection heat transfer coefficient - measurements and estimation. PrzeglądElektrotechniczny, 2014, 90, 5, 122125.

[20] Umbach K.H. "Tragekomfort mit zweiflächigen Textilien unter Verwendung von PP Fasern". ChemiefasernTextiindustrie, 1/1986 s. 64.

[21] M.Bühler, Ch. lyer. "Untersuchung und Weiterentwicklungsmöglichkeiten von funktionellen Maschenwaren auf Sportbekleidungssektor". Wirkerei und Strickerei Technik, 1986 nr 6 s. 611-615, Wirkerei und Strickerei Technik, 1986 nr 9 s. 904-911, Wirkerei und Strickerei Technik, 1986 nr 10 s. 1042-1047.

[22] Pillar B. "Integrierte Maschenwaren mit einem höheren Feuchtetransport". Wirkerei und Strickerei Technik, 7/1987 s. 721-728.

[23] E. Szucht. "Światowe kierunki rozwoju dzianin o wysokim komforcie fizjologicznym”. Technik Włókienniczy, 1990 nr 3, s. 85-88.

[24] K.H. Umbach. "Bekleidungsphysiologische Gesichtspunkte zur Entwicklung von Sportkleidung". Wirkerei und Strickerei Technik, 1993 nr 2 s. 108-114.

[25] K Kowalski, G. Wykin-Orlikowska, T. Manduk-Chuchla. "Właściwości biofizyczne dzianin $w$ badaniach laboratoryjnych i teście użytkowym". Przegląd Włókienniczy, 2003, nr 3, s.6-9.

[26] B. Wilbik-Hałgas, R. Danych B. Więcek, K. Kowalski. Air and Water Vapour Permeability in double-Layered Knitted Fabrics with Different Raw Materials Fibres \& Textiles in Eastern Europe. 2006 Vol. 14 Nr 3 s. 77- 81.

[27] Kowalski K., Janicka J., Massalska-Lipińska T., Nyka M. Impact of Raw Material combinations on the Biophysical Parameters and Underwear Microclimate of Two-Layer Knitted Materials. FIBRES \& TEXTILES in Eastern Europe 2010, Vol. 18, No. 5 (82) pp. 64-70.

[28] R.H. Wildnauer, R. Kennedy. Transepidermal water loss of human newborns, Journal of Investigative Dermatology, 1970, 54, 483-486.

[29] N. Rutter, D. Hull. Water loss from the skin of term and preterm babies, Archives of Disease in Childhood, 1979, 54, 11, 858-868.

[30] I. Krucińska, R.Korycki, E. Skrzetuska, K. Kowalski, A. Puszkarz, Wybrane zagadnienia z metrologii użytkowej odzieży funkcjonalnej, Monografia Politechniki Łódzkiej, ISBN 978-83-7283-808-7, Łódź, 2016.

[31] Newton Thermal Manikin Operator's Manual, Measurement Technology Northwest. 